\title{
Ecosystems and the Services They Provide
}

\author{
Molla Mekonnen Alemu ${ }^{1}$ \\ ${ }^{1}$ United Nations Development Programme, Freetown, Sierra Leone \\ Correspondence: Molla Mekonnen Alemu, Wilkinson 55, Freetown, Sierra Leone. Tel: 232-7906-1001. E-mail: \\ mollamekonnen@gmail.com
}

Received: February 8, 2016 Accepted: March 6, 2016 Online Published: April 4, 2016

doi:10.5539/jsd.v9n3p1

URL: http://dx.doi.org/10.5539/jsd.v9n3p1

\begin{abstract}
Every life form is dependent on ecosystem services for food, water, fiber, ecological regulation and societal values. During the past 50 years, human beings interfered in to the wellbeing of these ecosystems and the services they provide, mainly to fulfill the ever increasing demand of humans. Many ecosystems are being degraded by putting their ecological services in jeopardy and causing considerably irremediable losses of biodiversity from the face of the earth. The degradation of these resources is also expected to grow in the years to come by posing a threat to the wellbeing of humanity in various forms. The threat, therefore, needs a collaborated action from grass root to global level entities and bodies. Strong policy, strategy and institutional frameworks and action plans could also play a role in averting the ongoing degradation of the ecosystem services. This paper is therefore, aimed at highlighting the major ecosystem services and some possible measures that will help to mitigate the degradation of their services.
\end{abstract}

Keywords: ecosystem services, degradation, environment, biodiversity

\section{Introduction}

Ecosystems are composed of the biological living things community (animals, plants and organisms that interact with each other) in an area and the chemical as well as physical elements of the environment such as climate, weather, atmosphere, etc. (Walt, 2008).

In the natural world, the whole thing is interrelated. In the context of ecosystems the living and the non-living actors will work together. Ecosystems do not have a precise size. It can be small like a tree or sapling and can also be big like a lake or a desert. The sun light, edaphic factors, plants, animals, water, etc. they all work together. If one of these is affected by internal and external factors the entire system will be affected in one way or another. If the soil doesn't have enough nutrients, air or water plants will not be able to grow. If the plants can't grow herbivorous animals will not be able to survive and if the herbivores are not there the carnivores cannot exist. In the reverse order if there are no carnivores the herbivores can be a threat to the plants. In the ecosystem, all the different factions of life depend on each other and make a balanced system of life that controls the different geochemical and biophysical interactions and processes of the environment (NHPT, 2015).

Ecosystems and the biodiversity they contain are the foundations of life on the face of the earth. They form the fundamental natural climatic regulation processes which are the basis for supply of essentials to sustain life (food, water, clean air, fiber, etc.). Healthy ecosystems also have a role in regulating weather and climatic factors from local to global levels, whilst assisting in economic, social and political developments of a nation or a community. They also support the enhancement of livelihood opportunities through, soil and water conservation, flood regulation, disaster risk reduction, food security and water supply. Ecosystems can also play a pivotal role in climate change by sequestering carbon.

Different regions of the world are gaining economic prosperity at the expense of ecosystem services. Many of the natural ecosystems are changed to yield different benefits, for instance more than 40 percent of the earth's surface is being used for agriculture. As a result, local and global ecosystems, however, are facing tremendous pressure as a result of the growing demand of the ever increasing population rate of the globe. This is also affecting the future of sustainable development through biodiversity loss, climate change and different forms of disaster like flood. However, if these alarm have to be altered, different actors of development (Government, civil society organizations, academia, the private sector, communities) need to have a coordinated action as all the entities have a paramount role in overcoming this global challenge (UNEP, 2010). 


\section{Objective}

The paper is aimed at highlighting the major services of ecosystems, their current challenges and some possible measures that could help to mitigate the degradation of their services.

\section{Methodology}

For the compilation of this paper, different literatures on ecosystems and the services they provide were reviewed from books, journals and proceedings. The practical field level experiences and observations were also captured in the synthesis of the paper. The paper also tried to pinpoint some of the policy and strategy issues that need to be considered by decision makers if the services of the various ecosystems need to be maintained in a sustained way.

\section{Result and Discussion}

\subsection{The concept of Ecosystem}

Different scholars defined ecosystem in different ways. Vreugdenhil et al., (2003) however, mentioned that Christopherson's (1997) definition looks reasonably feasible, but there are also some others too. Accordingly, an ecosystem is defined as a natural system consisting of all plants, animals and microorganisms (biotic factors) in an area functioning together with all the non-living physical (abiotic) factors of the environment.

Vreugdenhil et al., (2003) and BO (2008) also said that the term ecosystem was created in 1930 by Roy Clapham, so as to designate the biological and physical elements of an environment which was considered in relation to each other as a unit. At later times the British ecologist Arthur Tansley has later developed the term by describing it as the interactive system established between biocoenosis (a group of living creatures) and their biotope (the environment in which they live).

The online dictionary of biology also defined ecosystem as a system that includes all living organisms (biotic factors) in an area as well as its physical environment (abiotic factors) functioning together as a unit (BO, 2008).

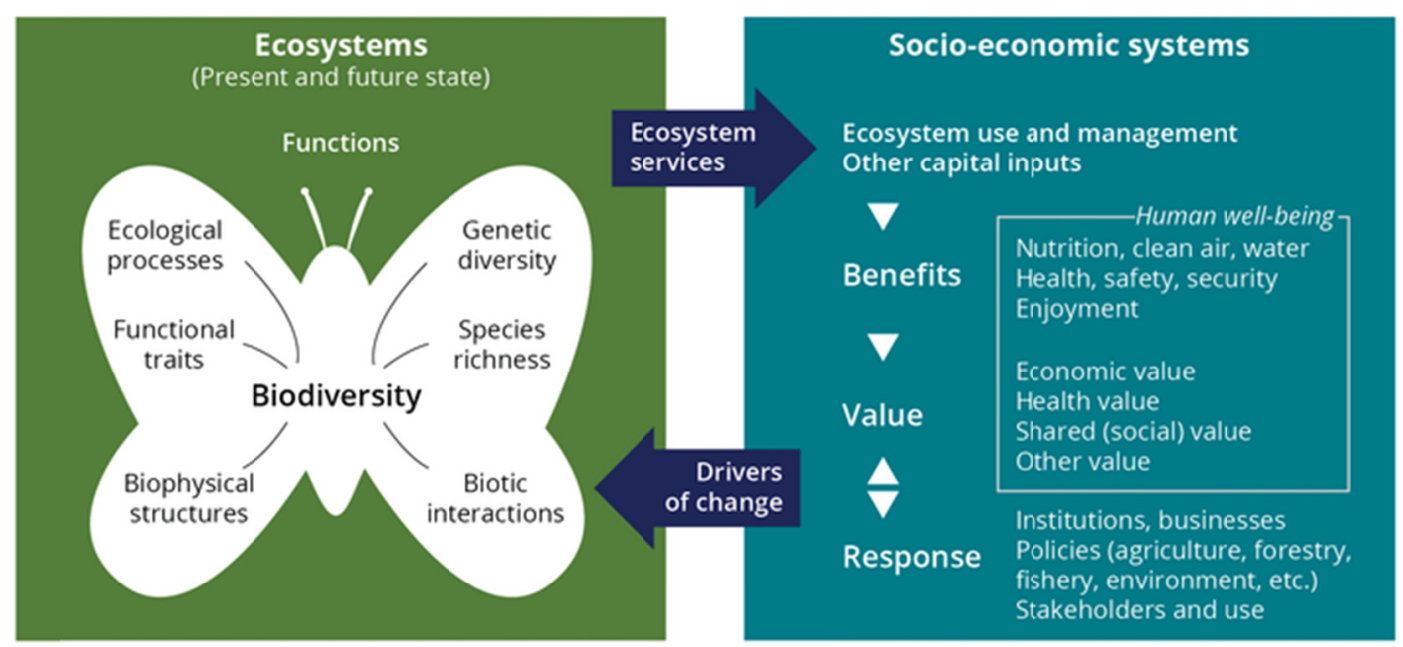

Figure 1. Conceptual framework for ecosystem assessment (EEA, 2015)

At the heart of the ecosystem concept is the continued interaction among animals, plants, edaphic factors, water and the atmosphere, whereby their interaction creates a dynamic relationship unit that supports their survival and existence as one cannot live without its direct and indirect interaction with the entire system.

An ecosystem can be considered sustainable if it is healthy, whereby all living forms will have the chance of reproducing themselves, which shows as there is a biologically active biodiversity in that environment.

Essentials that ensure the survival of humanity are obtained as a result of the very existence of healthy and diverse ecosystems. This includes the production of goods and services like food, fiber, clean water, clean air, timber, environmental development and protection, formation and recycling of nutrients, decomposition of 
wastes, aesthetic value and the protection and conservation of genetic diversity that ensures the survival of mankind.

\subsection{Ecosystem Services}

UKNEA (2012) defined ecosystem services as "the benefits provided by ecosystems that contribute to making human life both possible and worth living." Ecosystem services support the survival of human beings either directly or indirectly. UKNEA, (2012) also explained the term 'services' encompass the tangible and intangible benefits that humans obtain from ecosystems, which are sometimes separated into 'goods' and 'services'.

The Environment Agency of Europe has formulated the Common International Classification of Ecosystem Services that classifies the services of ecosystems in to three broad groups - provisioning, maintenance and regulation and cultural services (Sara, 2015).

\section{USAID Mariec}

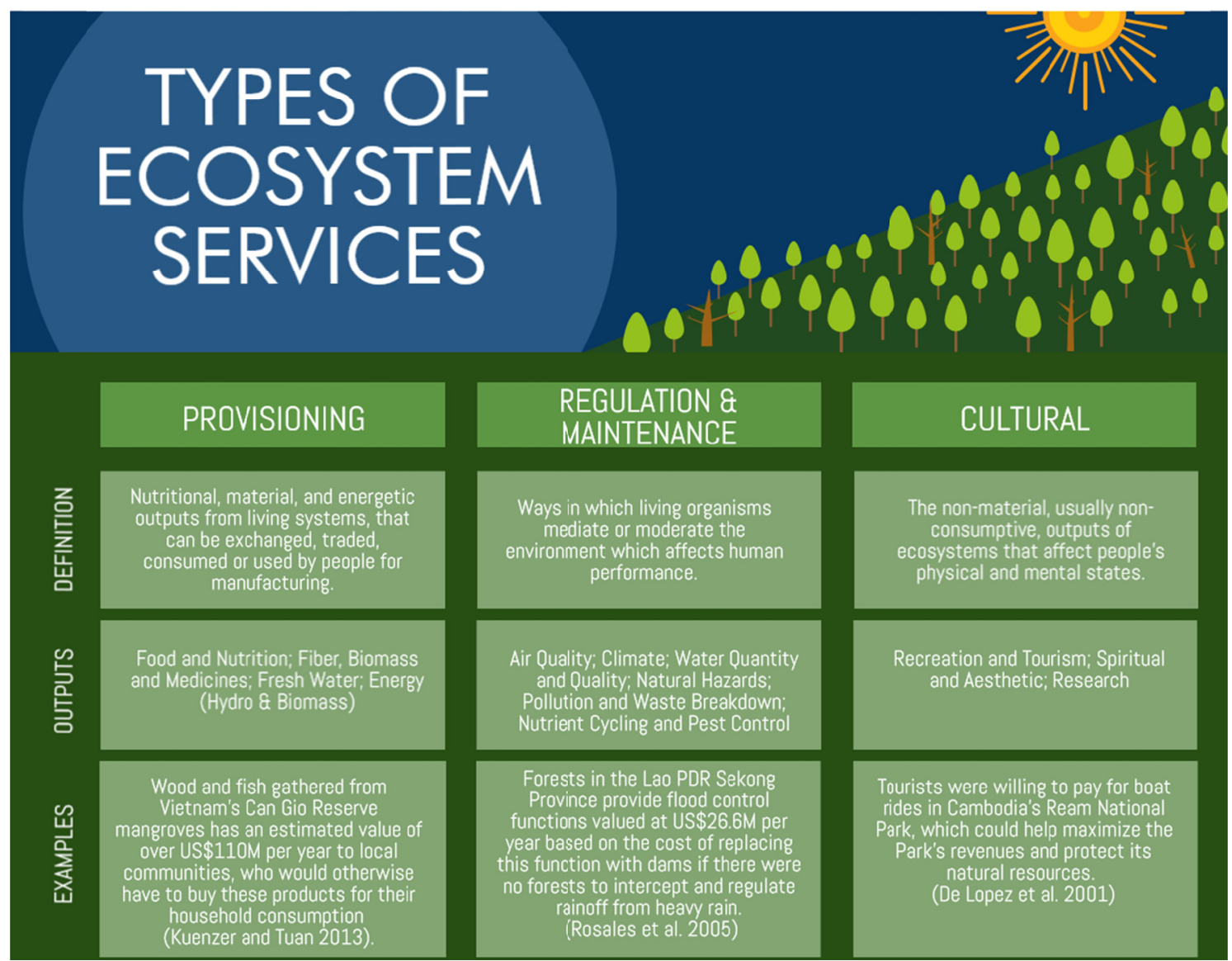

Figure 2. Types of ecosystem services (Sara, 2015)

Ecosystems provide services that ensure the survival of life forms on the planet. Different products could include, water, food, medicine, protection from flood and soil erosion, fiber, timber and control of pest and disease outbreaks. Recreational and spiritual values are also among the services which a healthy ecosystem could provide. Other services of ecosystems could also include, but not limited to are the formation of soil and nutrients, nutrient recycling, carbon sequestration, shelter for wild animals, etc. In general, ecosystems are the basis for the survival of humanity in one way or another (UKNEA, 2012).

It is however, a sad fact that many ecosystems are being interfered by anthropogenic factors as a result of the ever increasing population and as a result of this a wider portion of the earth's surface along with its inhabitants are facing manifold forms of disaster (flood, drought, disease, hunger, climate change, etc.).

According to WRS (2005), based on the Millennium Ecosystem Assessment result about 60 percent (15 out of 
24) of the ecosystem services are currently going through a sever degradation and unsustainable utilization of resources, mainly caused by the increase in food production for the growing population. As the resources are being used unsustainably, it is also believed as the current situation is putting the future generation in jeopardy. Apart from these, this alteration of the ecology is also affecting the wider segment of the population - urban and rural poor since it is directly affecting the cost of living and by widening inequalities among communities. It is also unlikely that the major causes of ecosystems degradation to become less. As a result, a lot of development ventures like poverty alleviation, health services, etc. will be affected directly for lack of synergy to combat the end results of ecosystem services degradation.

The conservation and development of natural capital is therefore, a pressing need which needs the strong attention of development actors at all levels. Though, actions are being taken presently to develop ecosystem services, more coordinated action still in its infant stage. Policy and strategic directions need to be materialized so as to preserve the dying biodiversity resources of the planet earth. A holistic and integrated ecosystem based development model needs to be effected by centering human development and the health of ecosystems. Institutional capacity development programmes has to be centered and focused on maintain the remaining biodiversity resources so that the deleterious effects of ecosystem disturbance will have a reduced harm on the wellbeing of life forms on the globe. Since household energy demand is a great contributor for the clearing of forest ecosystems, the issues of energy security has to be followed up through the development of eco-friendly alternative energy sources and innovations. Local livelihoods and employment generations will also help in lowering down the dependence of local people on the remaining natural resources which are already under the threat of land resources degradation.

\section{Conclusion}

In all parts of the world, ecosystems provide the space for the survival and wellbeing of the immense biodiversity resources of the planet. The healthy and proper relationship and interaction of these diverse forms of life in the different ecosystems is the foundation for the wellbeing of humanity. It is however, a sad fact that the ecosystem services are facing a severe degradation as a result of increased demand for food, water, fiber and other necessity and luxury needs of mankind. Different ecosystems are no more in a position to provide their services that have supported immense biodiversity resources which humanity can't afford to live without it. Anthropogenic factors are affecting the health of forest resources, wetlands, different water bodies and other natural resources. Climate change on the other hand is posing a considerable threat on the health of ecosystems by compromising their ability to provide services which they used to. Therefore, there should be urgent action in enhancing the awareness from local to higher levels on the interwoven relationship of ecosystem services. Decision makers need to work reforming policy, strategy, institutional and legislative frameworks which can ease the health of ecosystem services. As ecosystem services don't know political borders, placing cross border ecosystem management systems and frameworks should also be given a strong emphasis along with an immediate action.

\section{References}

BO (Biology-Online). (2008). Ecosystem. Retrieved February 5, 2016, from http://www.biology-online.org/dictionary/Ecosystem

Braat, P., \& Brink, T. (2008). The case of not meeting the 2010 biodiversity target. Wageningen, Netherlands.

GF (Green Facts). (2015). Ecosystem services. Retrieved February 6, 2016, from http://www.greenfacts.org/glossary/def/ecosystem-services.htm

Lehman, S. (2015). Employing Ecosystems Service Valuation Guidelines to Solve Metaphysical Riddles and Make a Case for Conservation. USAID Mekong Adaptation and Resilience to Climate Change Project.

NHPT (New Hampshire Public Television). (2015). Ecosystems. Durham, NH 03824. Retrieved January 5, 2016, from http://www.nhptv.org/natureworks/nwepecosystems.htm

NPCC (Native Plant Conservation Campaign). (2015). Ecosystem Services. San Francisco, CA 94107. Retrieved February 7, 2016, from http://plantsocieties.cnps.org/index.php/conservation-economics

Sandra Naumann, et al. (2013). The Social Dimension of Ecosystem Based Adaptation. UNEP Policy Series, United Nations Environment Programme.

Shah, A. (1998). Why Is Biodiversity Important? Who Cares? Global Issues. Retrieved January 29, 2016, from http://www.globalissues.org/article/170/why-is-biodiversity-important-who-cares\#WhyisBiodiversityImport ant

UKNEA (UK National Ecosystem Assessment). (2012). Ecosystem Services. Retrieved February 6, 2016, from 
http://uknea.unepwcmc.org/EcosystemAssessmentConcepts/EcosystemServices/tabid/103/Default.aspx

UNEP. (2010). The Role of Ecosystems in Developing a Sustainable 'Green Economy'. Ecosystem Management Policy Brief, 2.

UNEP. (2011). Putting Ecosystem Management in the Vision of Africa's Development. Ecosystem Management Policy Brief, 7.

Vreugdenhil, D., Terborgh, J., Cleef, A. M., Sinitsyn, M., Boere, G. D., Archaga, V. L., \& Prins, H. H. T. (2003). Comprehensive Protected Areas System Composition and Monitoring, WICE, USA, Shep-herdstown.

Whitman, W. (2008). The Concept of Ecosystem. The Regents of the University of Michigan, USA.

WRI (World Resources Institute). (2005a). Ecosystems and Human Well-being. Washington, DC 20002.

WRS (World Resources Institute). (2005b). Ecosystems and Human Well-being: Synthesis. Millennium Ecosystem Assessment, 2005. Island Press, Washington, DC.

\section{Copyrights}

Copyright for this article is retained by the author(s), with first publication rights granted to the journal.

This is an open-access article distributed under the terms and conditions of the Creative Commons Attribution license (http://creativecommons.org/licenses/by/3.0/). 